\section{Particles in the sea}

Suspended Solids in Water. (Marine Sciences, vol. 4.) Edited by Ronald J. Gibbs. Pp. xiii + 320. (Plenum: New York and London, 1974.) \$34.90.

THE pioneering observations by N. G. Jerlov of the light-scattering properties of sea water, obtained during the Swedish Deep-Sea Expedition (1947-48), established their usefulness for delineating the distribution and relative concentrations of suspended particles in the sea. Interest in this topic has been revived fairly recently by advances in several disciplines, including those concerned with the influence of dilute particle suspensions on the stability and mechanism of finegrained sediment motion, with the widespread occurrence of high concentrations of particles close to the deep-sea floor (the so-called nepheloid layer) and with developments in marine optics, which have produced some novel designs of in situ light-scattering and transmission meters. This volume represents the proceedings of a symposium of the same title, held in Santa Barbara, California, during March 1973, at which recent work on these topics was intensively reviewed.

The first section of the book contains an introductory chapter by the editor and a chapter describing a theoretical study of the settling and reaction of particles in natural waters. In Section II, five chapters deal with the requirements of optical instruments for in situ use and the problems of measuring certain optical parameters of sea water. This section is a useful summary of the state-of-the-art.

Sections III and IV, occupying the major part of the book, contain case studies of suspended matter in nearshore and offshore environments using, in most cases, a combination of in situ lightscattering data and some measure of the total quantity of suspended material in discrete water samples. The interest here has been to use the optical data as a convenient measure of the concentration of suspended particles and then to examine the role of such material in the redistribution and sedimentation of organic and inorganic solids in the sea.

A particularly good example of an integrated approach to this type of problem is provided by Biscaye and Eittreim who describe a time series of observations of the nepheloid layer at two stations in the western North Atlantic, using measurements of excess radon to study the effect of vertical mixing on the distribution of bottom particles.

The last two chapters show that it is possible to identify sources of suspended particles from a knowledge of their chemical and mineralogical composition. This type of information will be required in studies of the generation and dissipation of nepheloid layers and the role hese layers might have in the overall sedimentary economy of the deep sea. What seems to be required is a calibration of these techniques by determining the major and minor element composition of suspended material over an entire water column, and not simply the nearbottom layers in isolation. Such information will, I hope, be made available by the GEOSECS programme of the US International Decade of Ocean Exploration.

S. E. Calvert

\section{Behaviour differences}

Sex Differences in Behavior. (Seminars in Human Reproduction.) Edited by Richard C. Friedman, Ralph M. Richart and Raymond L. Vande Wiele. Pp. xvi + 495. (Wiley: New York and London, December 1974.) $£ 12.50$.

THIs book contains 24 chapters by over 30 different authors, based on a conference held in New York in September 1973. The common theme is behavioural sex differences, but many of the chapters have little else in common. A wide variety of different approaches within psychology and biology are represented, so that the subject is considered from physiological, clinical, evolutionary, psychoanalytical, cognitive developmental, ethological, and experimental psychological viewpoints. Such diversity has resulted in a very uneven book, and this is further intensified by there being a mixture of research papers, surveys of an author's own research, and more general reviews.

The most useful chapters are those which present a survey of an author's own research, particularly where this covers several years' work. Such chapters include those by Moss, on human mother-infant interactions, Phoenix, on prenatal hormones and primate behaviour, Ehrhardt and Baker, on foetal androgens and human sex differences, Sackett, on sex differences in responses to maternal deprivation, Rosenblum, on mother-infant attachment in primates, and Green, on boys who preferred a feminine role. All of those chapters will be useful to research workers, and possibly to advanced undergraduates. Other chapters of that type-for example, that by Lewis and Weinraub on sex differences in infant attachment-are marred by the excessive detail the authors present in reporting their own data.

Chapters consisting of critical but selective reviews are also very useful in a book of this sort, and so are reviews which attempt to organise and integrate previous findings in a new way. I found the reviews by Meyer-Bahlberg, on the XYY syndrome, Levine, on sex differences in rats' responses to neonatal stress, Korner, on human neonatal differences, and Whalen, on problems and concepts in research on sexual differentiation, the most useful. Two other reviews, by Moyer, on sex differences in aggression, and Hamburg, on an evolutionary perspective on behavioural sex differences, both conspicuously lacked critical appraisal of their material. In addition, the former merely presented material which will be published elsewhere.

Several other chapters give incomplete accounts of research work in progress, sometimes based on very small samples, and thus meriting at best only a short report in a journal. For example, Michael et al. base a chapter on the bisexual behaviour of female monkeys simply on observations from two animals; Kohlberg and Ullian, on the development of gender concepts, report data from two subjects (out of 70 studied); MeyerBahlberg et al., on cryptorchidism and gender identity, use results from 10 subjects (out of 67 studied). Perksy's chapter on the menstrual cycle and psychological test measures also uses partly analysed data. The only really successful chapter reporting original experimental work is that of Doering et al., on testosterone and psychological test measures in men, and even that is really more appropriate for a journal.

Overall, the book is very diverse and very uneven, so that at $£ 12.50$ it is unlikely to attract many buyers. Parts of it will be useful to a wide variety of people for a wide variety of reasons, and I would anticipate that there will be a heavy demand for library copies. John Archer

\section{BOOKS ON PURE AND APPLIED SCIENCE}

Books reviewed or mentioned in this journal are available from stock.

Catalogues on application.

Please state interests.

\section{SCIENTIFIC LIBRARY}

ANNUAL SUBSCRIPTION from $£ 4.00$

Reduced rates for multiple subscriptions

Available in U.K. only

Prospectus free on request

\section{H. K. LEWIS \& Co. Ltd. \\ LONDON: 136 GOWER STREET,} WCIE 6BS

Telephone: $01-3874282$ 